$\left.\begin{array}{c}\text { Kalpa Publications in Engineering } \\ \text { Volume 3, 2020, Pages 65-73 } \\ \text { Proceedings of International Sym- } \\ \text { posium on Applied Science 2019 }\end{array}\right)$ Kalpel

\title{
Improving Quality Control Of Operating Room Environment By Computational Fluid Dynamics
}

\author{
Tich Thien Truong ${ }^{1 *}$, Quoc Bao Cao ${ }^{1}$ \\ ${ }^{1}$ Ho Chi Minh City University of Technology, Viet Nam National University Ho Chi Minh City. \\ tttruong@hcmut.edu.vn
}

\begin{abstract}
In Vietnam, the operating room (OR) is used with max productivity. So, how to maintain comfort environment level, which is one of the assignments in designing and installing the operating room. In this study, the OR model is designed based on ASHRAE $170-2013$ standard [1], and dimensions are referred to as "Comparison of Operating Room Ventilation System in the Protection of the Surgical Site" [2]. ANSYS CFX is used for calculating and simulating velocity and temperature of surveyed air points inside the room by many cases. A face temperature between 20.3 and $20.6{ }^{\circ} \mathrm{C}$ and a velocity of around 0.15 to $0.18 \mathrm{~m} / \mathrm{s}$ is provided from the same laminar diffuser array. From the results, the OR comfort level is reviewed through the ADPI index.
\end{abstract}

\section{Introduction}

For the first time, the cleanroom is used in the medical field, beginning with the research of Pasteur, Koch, Lister. Currently, the healthcare sector is being developed more than ever before to meet the needs of population growth, so the environmental quality inside the OR must be improved. A high level of the comfortable surgical room will enhance the surgery success rate.

The purpose of this study is to design and simulate airflow inside the operating room with ANSYS CFX software version 18.1, which gives an overview of the airflow as well as the air velocity and temperature. From the simulation results of the operating room model with different input conditions (temperature, the velocity of the air diffuser) will calculate the ADPI index. Since then, the study will assess the comfort level of the operating room's inner environment for each case and provide a comment on effectiveness. 


\section{Overview And Governing Equations Of Computational Fluid Dynamics}

The Navier - Stokes equations describe transmission processes the momentum, heat, and mass. These differential equations appeared in the early nineteenth century, although no general analytical solution was known but could be solved and solved by numerical methods.

\subsection{The Navier-Stokes equations}

Navier-Stokes equations are built from the conservation of mass, momentum, and energy for any volume under consideration. The most general form of the Navier-Stokes equation system [3]:

where:

$$
\rho(\partial \mathbf{U} / \partial \mathrm{t}+\mathbf{U} . \nabla \mathbf{U})=-\nabla \mathrm{p}+\nabla \mathrm{T}+\rho \mathbf{g}
$$

The left side of the equation describes acceleration and may be composed of time-dependent and convective components (also the effects of non-inertial coordinates if present) including:

- $\rho:$ density.

- U: flow velocity.

- $\quad \partial \mathrm{U} / \partial \mathrm{t}$ : instantaneous acceleration. U.VU: convective acceleration.

- The right side of the equation is in effect a summation of hydrostatic effects, the divergence of deviatoric stress and body forces (such as gravity) including:

- $\quad$ : pressure.

- $\quad \nabla \mathrm{T}$ : the divergence of the deviatoric stress tensor.

- $\quad$ g: body accelerations acting on the continuum.

This is the momentum conservation law in fluid, The Newton's second law is applied to a continuum. This equation is often written as a derivative:

$$
\rho \mathrm{d} \mathbf{U} / \mathrm{dt}=-\nabla \mathrm{p}+\nabla \mathrm{T}+\rho \mathbf{g}
$$

\subsection{Turbulence model $\mathrm{k}-\varepsilon$ in ANSYS CFX}

Most industrial flows are turbulence, so ANSYS CFX always takes a special interest in creating top turbulence models to obtain the impact of turbulence accurately and efficiently. The k- $\varepsilon$ model introduces two new variables into the system of equations. Continuous equations are [4]:

$$
\partial \rho / \partial \mathrm{t}+\partial\left(\rho \mathrm{U}_{\mathrm{j}}\right) / \partial \mathrm{x}_{\mathrm{j}}=0
$$

The momentum equation becomes:

$$
\partial \rho \mathrm{U}_{\mathrm{i}} / \partial \mathrm{t}+\partial\left(\rho \mathrm{U}_{\mathrm{i}} \mathrm{U}_{\mathrm{j}}\right) / \partial \mathrm{x}_{\mathrm{j}}=-\partial \rho / \partial \mathrm{x}_{\mathrm{i}}+\partial\left[\mu_{\mathrm{eff}}\left(\partial \mathrm{U}_{\mathrm{i}} / \partial \mathrm{x}_{\mathrm{j}}+\partial \mathrm{U}_{\mathrm{j}} / \partial \mathrm{x}_{\mathrm{i}}\right)\right] / \partial \mathrm{x}_{\mathrm{j}}+\rho \mathbf{g}
$$

Where:

- $\mu_{\text {eff: }}$ : the effective viscosity accounting for turbulence.

- $\rho$ : the modified pressure.

The k- $\varepsilon$ model, like the zero-equation model, is based on the eddy viscosity concept, so that:

where $\mu \mathrm{t}$ is the turbulence viscosity.

$$
\mu_{\text {eff }}=\mu+\mu_{\mathrm{t}}
$$

The values of $\mathrm{k}$ and $\varepsilon$ come directly from the differential transport equations for the turbulence kinetic energy and turbulence dissipation rate:

$$
\partial(\rho \mathrm{k}) / \partial \mathrm{t}+\partial\left(\rho \mathrm{U}_{\mathrm{i}} \mathrm{k}\right) / \partial \mathrm{x}_{\mathrm{i}}=\partial\left[\partial \mathrm{k} / \partial \mathrm{x}_{\mathrm{i}}\left(\mu+\mu_{\mathrm{t}} / \sigma_{\mathrm{k}}\right)\right] / \partial \mathrm{x}_{\mathrm{i}}+\mathrm{P}_{\mathrm{k}}-\rho \varepsilon+\mathrm{P}_{\mathrm{kb}}
$$

$\partial(\rho \varepsilon) / \partial \mathrm{t}+\partial\left(\rho \mathrm{U}_{\mathrm{i}} \varepsilon\right) / \partial \mathrm{x}_{\mathrm{i}}=\partial\left[\partial \varepsilon / \partial \mathrm{x}_{\mathrm{i}}\left(\mu+\mu_{\mathrm{t}} / \sigma_{\varepsilon}\right)\right] / \partial \mathrm{x}_{\mathrm{i}}+\varepsilon / \mathrm{k}\left(\mathrm{C}_{1 \varepsilon} \mathrm{P}_{\mathrm{k}}-\rho \mathrm{C}_{2 \varepsilon} \rho \varepsilon+\mathrm{C}_{\varepsilon 1} \mathrm{P}_{\varepsilon \mathrm{b}}\right) \partial \mathrm{t}$

With $\mu_{\mathrm{t}}=\rho \mathrm{C}_{\mu} \mathrm{k}^{2} / \varepsilon$.

- $\mathrm{P}_{\mathrm{kb}} ; \mathrm{P}_{\varepsilon b}$ represents the influence of the buoyancy forces.

$\mathrm{Pk}$ is the turbulence production due to viscous forces, which is modeled using: 


$$
\mathrm{P}_{\mathrm{k}}=\mu_{\mathrm{t}}\left(\partial \mathrm{U}_{\mathrm{i}} / \partial \mathrm{x}_{j}+\partial \mathrm{U}_{\mathrm{j}} / \partial \mathrm{x}_{i}\right) \partial \mathrm{U}_{\mathrm{i}} / \partial \mathrm{x}_{\mathrm{j}}-\left(2 \partial \mathrm{U}_{\mathrm{k}} / 3 \partial \mathrm{x}_{\mathrm{k}}\right)\left(3 \mu_{\mathrm{t}} \partial \mathrm{U}_{\mathrm{k}} / \partial \mathrm{x}_{\mathrm{k}}+\rho \mathrm{k}\right)(8)
$$

The tangled model uses constant values such as: $\mathrm{C}_{1 \varepsilon}=1.44 ; \mathrm{C}_{2 \varepsilon}=1.92 ; \mathrm{C}_{\mu}=0.09 ; \sigma_{\mathrm{k}}=1 ; \sigma_{\varepsilon}=1.3$. These values apply effectively within the range of non-stressed fluid flows and closure fluid flows.

\subsection{ASHRAE standard 170-2013}

The OR model in this study was designed based on the parameters of [2] and adopted the ASHRAE standard 170-2013 [1]:

- Minimum guidelines for a modern OR sized $20 \mathrm{ft} \times 20 \mathrm{ft}(6.1 \mathrm{~m} \times 6.1 \mathrm{~m})$.

- The air supply grid will provide laminar flow.

- Ceiling height between $9 \mathrm{ft}$ and $12 \mathrm{ft}(2.7 \mathrm{~m}$ and $3.7 \mathrm{~m})$.

- Ceiling grid size between $6 \mathrm{ft} \times 8 \mathrm{ft}(1.8 \mathrm{~m} \times 2.4 \mathrm{~m})$ and $8 \mathrm{ft} \times 8 \mathrm{ft}(2.4 \mathrm{~m} \times 2.4 \mathrm{~m})(12 \%$ to $16 \%$ ceiling coverage).

- The air change rate of 20 to 25 per hour.

- Laminar diffuser array face velocity of 25 to $35 \mathrm{fpm}(0.12$ to $0.18 \mathrm{~m} / \mathrm{s})$.

- Room pressurized to 0.01 in. w.c. (2.5 Pa) positive to the adjacent space.

The air exits the room through the number of outlets - from two to four outlets are placed on two specified walls.

\subsection{Thermal acceptance regions of EDT for heating mode}

According to Professor Pham Ngoc Dang, when the temperature $t_{h q} \geq 27^{\circ} \mathrm{C}$ with the room wind speed from 0.2 to $0.5 \mathrm{~m} / \mathrm{s}$ corresponding to the air temperature in the room $t_{t}=(29-30)^{\circ} \mathrm{C}$, which creates a sense of discomfort.

The ADPI index (Air Diffusion Performance Index) depends on the air velocity and the EDT index (Effective Draft Temperature). The EDT index can be calculated by the formula [5]:

Where:

$$
\operatorname{EDT}(\theta)=\mathrm{T}_{\mathrm{i}}-\mathrm{T}_{\mathrm{a}}-8\left(\mathrm{~V}_{\mathrm{i}}-0.15\right)^{\circ} \mathrm{C}
$$

- $\mathrm{T}_{\mathrm{i}}$ : the local temperature of airflow at the investigating point.

- $\mathrm{T}_{\mathrm{a}}$ : the average temperature of the investigating space.

- $\mathrm{V}_{\mathrm{i}}$ : the local velocity of airflow.

While the ADPI index is known as the ratio between the total number of points with the EDT index within the standard range $\left[-1.7^{\circ} \mathrm{C} ; 1.1^{\circ} \mathrm{C}\right]$ and the airflow velocity below or equal to $0.35 \mathrm{~m} / \mathrm{s}$ with Total points measured. The human body only feels comfortable in spaces with an ADPI index of $0.8(80 \%)$ or more.

The above formula is a means of assessing an area's perceived level (cold or warm) of the human body due to the influence of temperature and the speed of air movement in the environment.

\section{Validation}

The result of the analysis will be compared with the experiment by using the overall average error calculations and absolute error due to the following equation:

Where:

$$
\mathrm{E}=\left(\sum_{\mathrm{i}=1}^{\mathrm{n}}\left|\mathrm{T}_{\mathrm{CFD}}^{\mathrm{i}}-\mathrm{T}_{\mathrm{tn}}^{\mathrm{i}}\right| / \sum_{\mathrm{i}=1}^{\mathrm{i}} \mathrm{T}_{\mathrm{tn}}^{\mathrm{i}}\right) * 100 \%
$$

- $\quad \mathrm{n}$ : number of measurements. T: air temperature (K). 


\subsection{Problem 1}

The problem is based on the experimental model "An Experimental Study of Air Flow and Temperature Distribution in a Room with Displacement Ventilation and a Chilled Ceiling" [6]. The problem is to simulate room space working with a heat source and using the k- $\varepsilon$ turbulence model to calculate.

Input condition (Air diffuser): $1.5 \mathrm{ACH}$ (ventilation rate); $0.0548 \mathrm{~m} / \mathrm{s}$ (velocity); $\mathrm{Ts}=19^{\circ} \mathrm{C}$ (temperature).

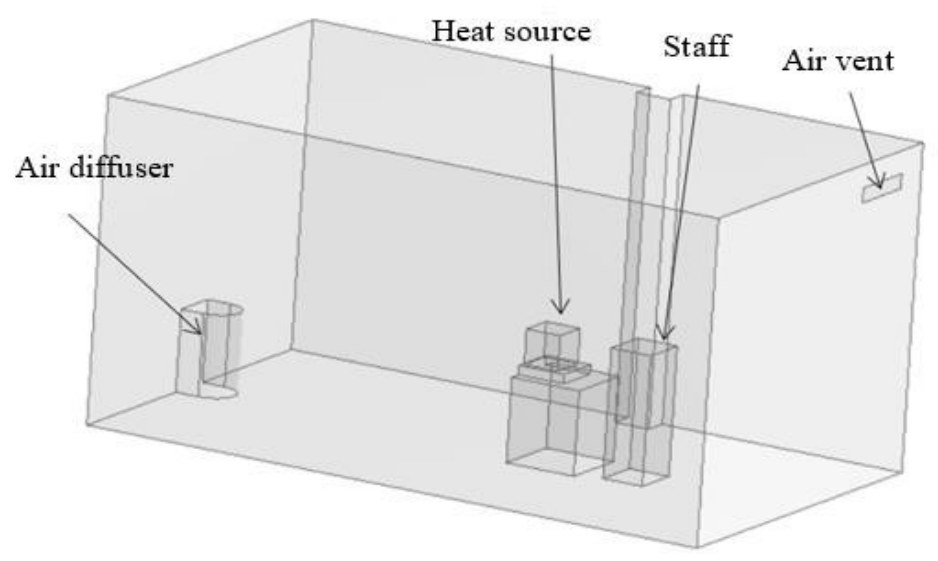

Figure 1: Schematic geometry of problem 1.

\begin{tabular}{llll}
\hline Description & Position & Boundary type & Heat information \\
\hline Heat source & monitor & Wall & $18 \mathrm{~W} / \mathrm{m}^{2}$ \\
\hline Staff & human & Wall & $37^{\circ} \mathrm{C}$ \\
\hline Ceiling & celling & Wall & $0.64 \mathrm{~W} / \mathrm{m}^{2} . \mathrm{K}$ \\
\hline Floor & floor & Wall & $0.41 \mathrm{~W} / \mathrm{m}^{2} . \mathrm{K}$ \\
\hline Exhaust & outlet & Opening & Temperature: $20^{\circ} \mathrm{C}$ \\
& & & Pressure: $0 \mathrm{~Pa}$ \\
\hline
\end{tabular}

Table 1: Details of boundary condition.

The simulation problem with ANSYS CFX achieved a good temperature result when the error with the experiment is $8.46 \%$. 


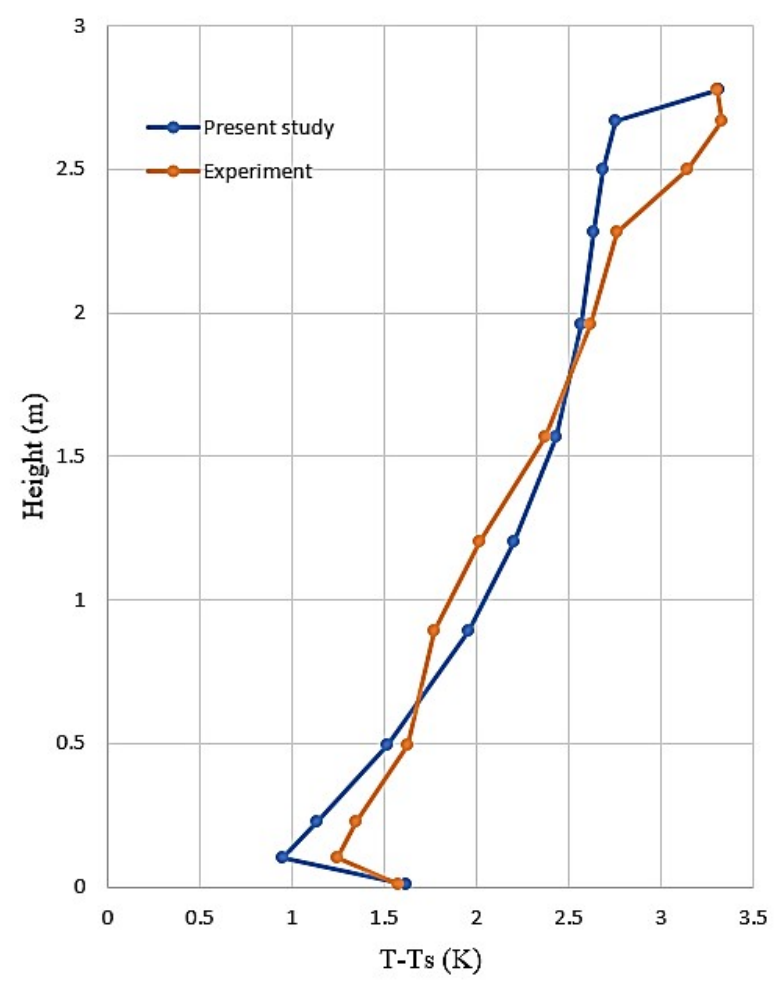

Figure 2: The Results of the comparison between simulation and experiment.

\subsection{Problem 2}

The problem was set up to test based on the Workshop 3: Room Temperature Study [7], with given room sizes and boundary conditions, the problem was solved in steady mode. This problem was solved by ANSYS CFX version 18.1 with the following boundary condition: inlet (vent, computer vent), opening (outlet), outlet (computer intake), wall (others).

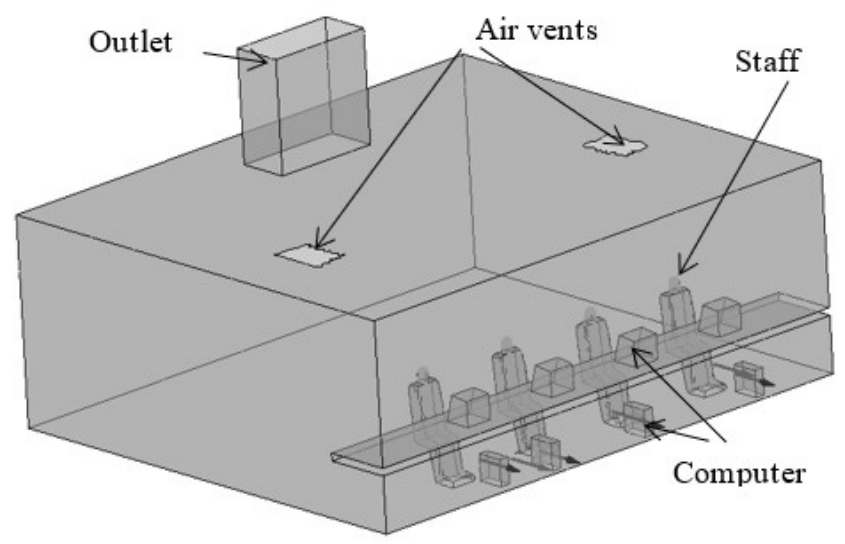

Figure 3: Schematic geometry of problem 2. 

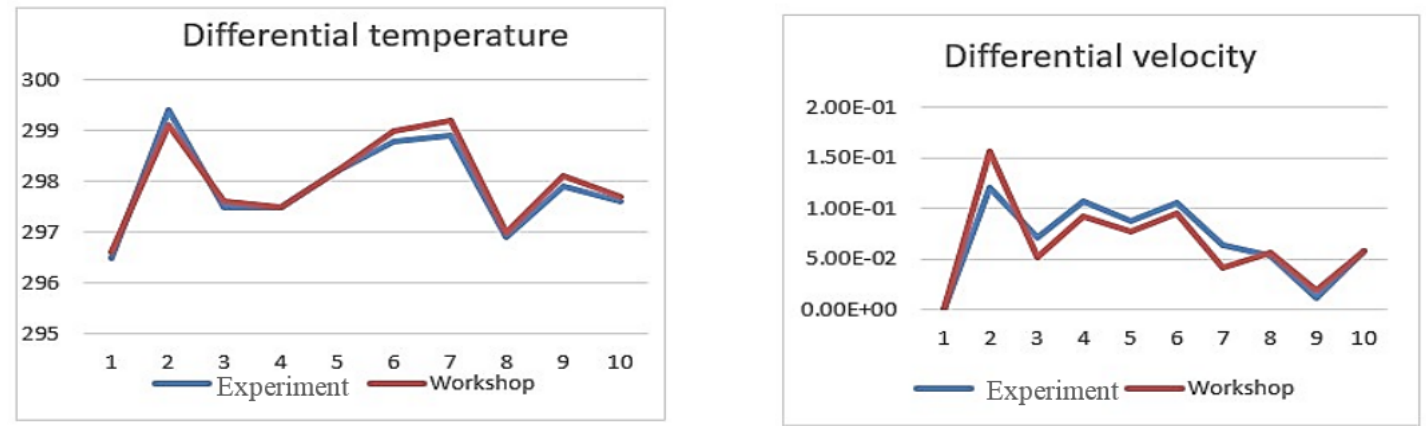

Figure 4: Temperature and velocity difference between research and workshop.

The comparison obtained a good agreement between the present work and published data. The difference in temperature and velocity values is $0.047 \%$ and $18.7 \%$ respectively.

\section{Simulation Model Establishment}

\subsection{Operating room dimensions}

Operating room dimensions were designed base on ASHRAE standard 170-2013 [1] and article [2]: the size of the surgery room model: $6.1 \mathrm{~m}$ x $6.1 \mathrm{~m} \times 3.66 \mathrm{~m}$. The room includes four surgeons, one patient, two surgical lights, an anesthesia machine, an operating table, an inactive machine, two computer monitors (shelving).

In this study, the operating room model with dimensions as shown in table 2 , the applied boundary conditions: inlet (air diffuser), openings (exhaust grilles), wall (the others).

\begin{tabular}{|c|c|c|}
\hline Item & Dimensions (mm) & $\begin{array}{l}\text { Heat } \\
\text { Dissipation }\end{array}$ \\
\hline Surgical lights (x2) & 600 diameter & $200 \mathrm{~W}$ each \\
\hline Overhead lights $(\times 4)$ & $1.830 \times 300$ (long $\mathrm{x}$ wide) & $180 \mathrm{~W}$ each \\
\hline $\begin{array}{l}\text { Surgical staff members } \\
(\mathrm{x} 4)\end{array}$ & 1.650 high & $100 \mathrm{~W}$ each \\
\hline One patient & 1.650 high & $100 \mathrm{~W}$ \\
\hline Monitors (x2) & $460 \times 350 \times 250$ (long $\times$ wide $\times$ high) & $200 \mathrm{~W}$ each \\
\hline Stand $(\times 2)$ & $600 \times 300 \times 1.200$ (long $\times$ wide $\times$ high) & \\
\hline Anesthesia machine & $750 \times 750 \times 1100$ (long $\mathrm{x}$ wide $\mathrm{x}$ high) & $200 \mathrm{~W}$ \\
\hline Machine1 & $750 \times 750 \times 750$ (long $\times$ wide $\times$ high) & \\
\hline Operating table & 2.000 x 750 x 900 (dài x rộng x cao) & \\
\hline Back table & $1.500 \times 750 \times 760$ (long $\times$ wide $\times$ high) & \\
\hline Exhaust grilles $(\mathrm{x} 4)$ & $610 \times 360$ (long $\times$ wide) & \\
\hline
\end{tabular}




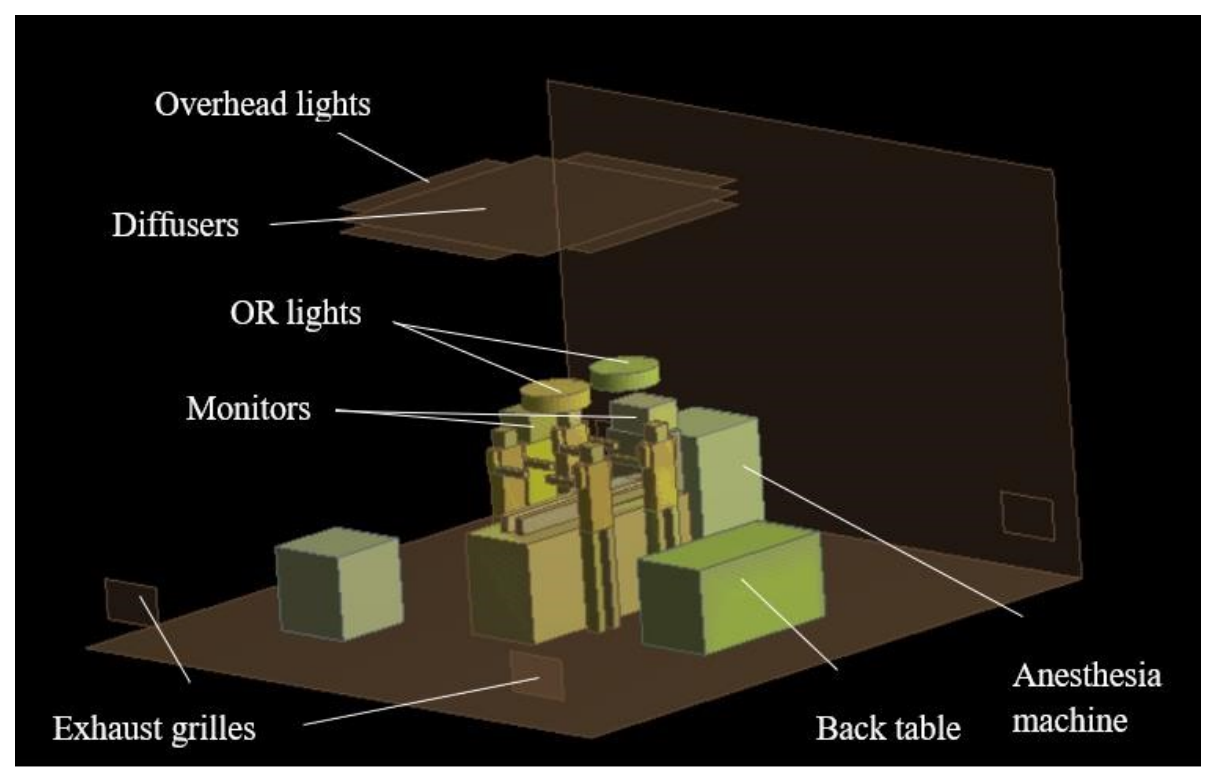

Figure 5: Operating room model Four exhaust grilles were located $300 \mathrm{~m}$ from the floor.

\section{Results And Discussion}

This study simulated the problem with the following cases:

\begin{tabular}{llll}
\hline & Case 1 & Case 2 & Case 3 \\
\hline Input velocity $(\mathrm{m} / \mathrm{s})$ & $0.15 \mathrm{~m} / \mathrm{s}$ & $0.15 \mathrm{~m} / \mathrm{s}$ & $0.16 \mathrm{~m} / \mathrm{s}$ \\
\hline Temperature $\left({ }^{\circ} \mathrm{C}\right)$ & 20.3 & 21 & 20.3 \\
\hline
\end{tabular}

Table 3. Initial conditions of the air diffuser.

In each case, the study will examine the temperature and velocity in the operating room environment at 15 points, including the locations around the surgical table, medical instrument table, and assistive devices. Those are the position of the surgical staff working and the location of the patient being located.

For each case, the EDT index is calculated according to (9). From the obtained result, the comfort level of the environment inside the operating room will be assessed through the ADPI index.

Case 1:
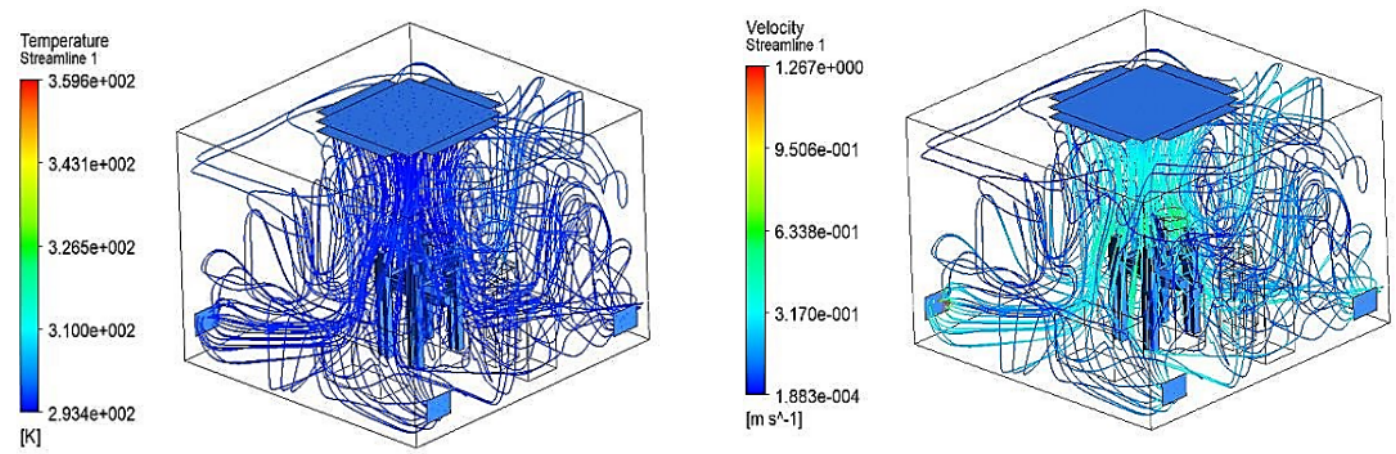

Figure 6: Temperature and velocity distribution in case 1 
Case 2:

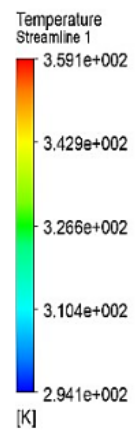

Case 3:
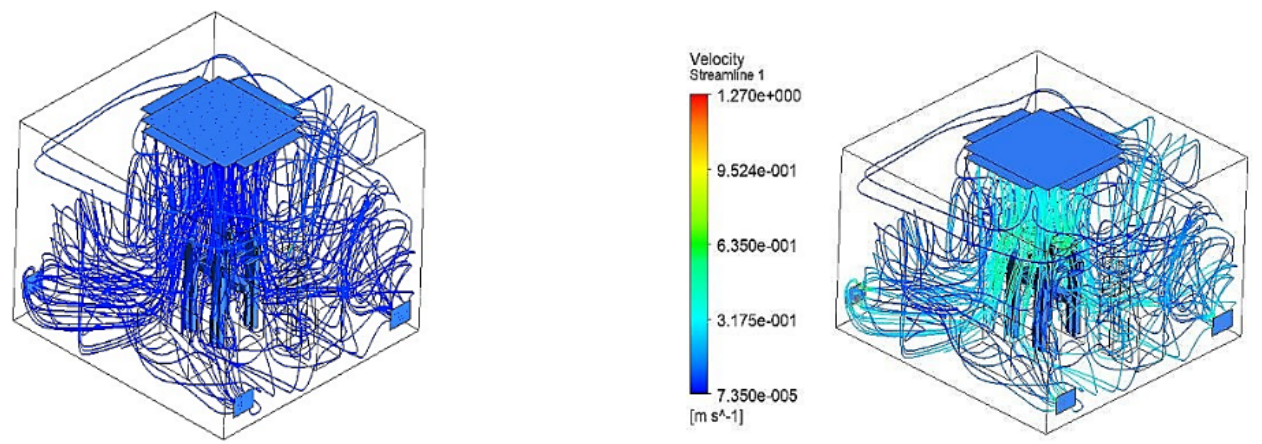

Figure 7: Temperature and velocity distribution in case 2.
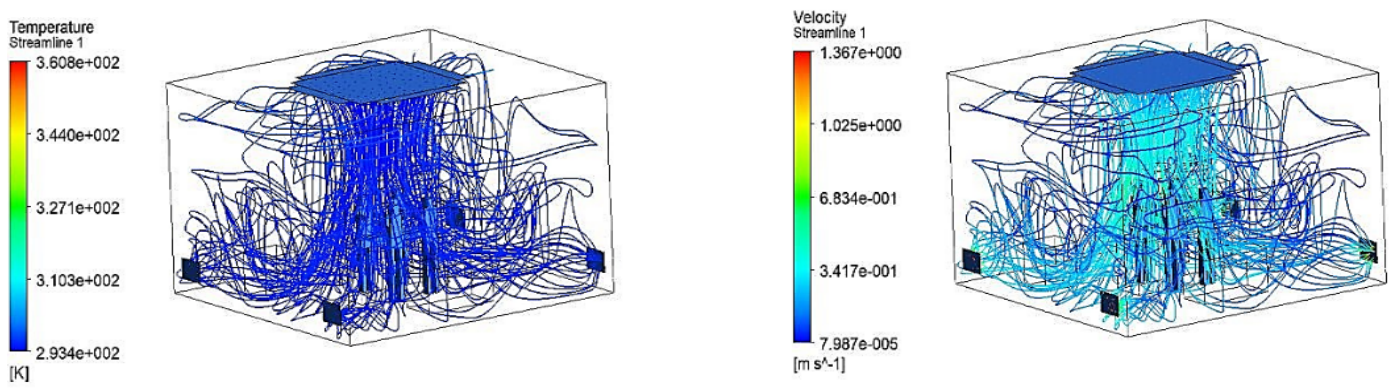

Figure 8: Temperature and velocity distribution in case 3.

The ADPI index results are shown in the following table:

\begin{tabular}{llll}
\hline Case & Average temperature $\left({ }^{\circ} \mathrm{C}\right)$ & EDT index & ADPI index (\%) \\
\hline 1 & 23.336 & $13 / 15$ & 86.667 \\
\hline 2 & 24.045 & $12 / 15$ & 80 \\
\hline 3 & 23.221 & $14 / 15$ & 93.333
\end{tabular}

Table 4. ADPI for three case

\section{DISCUSSION}

With the simulation model, the air diffuser provides laminar flow, so the airflow tends to move from the ceiling to the floor. From the results, the ADPI index in case 3 is the highest. In general, the change in velocity or temperature does not affect the movement of the airflow and comfortable conditions inside the room. The operating room is designed according to ASHRAE standards to meet the standard of comfort in the working environment inside the room.

\section{Acknowledgments}

The research was funded by the University of Technology, Vietnam National University - Ho Chi Minh City in the framework of the project code SVCQ - 2018 - KHUD - 122. The authors sincerely 
thank The University of Technology, Vietnam National University - Ho Chi Minh City for creating everything favorable conditions to carry out this research.

\section{References}

1. ASHRAE Standard - Ventilation of Health Care Facilities, 170 (2008).

2. Farhad Memarzadeh, Andrew P. Manning - Comparison of Operating Room Ventilation Systems in the Protection of the Surgical Site (2002).

3. Batchelor, (1967) 137-142.

4. ANSYS, Inc Proprietary. ANSYS CFX-Solver Theory Guide, ANSYS, Inc., (2017).

5. A. Liu - Air Diffusion Performance Index (ADPI) of diffusers for heating mode, Building and Environment vol 8 (2015) 215-223.

6. Simon J. Reesa, Philip Havesb - An Experimental Study of Air Flow and Temperature Distribution in a Room with Displacement Ventilation and a Chilled Ceiling.

7. ANSYS, Inc Proprietary - Workshop 3: Room Temperature Study, Introduction to ANSYS CFX, (2010). 